\title{
Paideusis
}

\section{Acquiring Practical Knowledge: A Justification for Physical Education}

\section{Sheryle Bergmann Drewe}

Volume 12, Number 2, 1999

URI: https://id.erudit.org/iderudit/1073088ar

DOI: https://doi.org/10.7202/1073088ar

See table of contents

Publisher(s)

Canadian Philosophy of Education Society

ISSN

0838-4517 (print)

1916-0348 (digital)

Explore this journal

Cite this article

Drewe, S. (1999). Acquiring Practical Knowledge: A Justification for Physical

Education. Paideusis, 12(2), 33-44. https://doi.org/10.7202/1073088ar viewed online.

https://apropos.erudit.org/en/users/policy-on-use/ 


\section{Acquiring Practical Knowledge: A Justification for Physical Education}

\section{Sheryle Bergmann Drewe, University of Manitoba}

During this time of cost-cutting and the back-to-basics movement, physical educators must provide persuasive arguments for the inclusion of physical education in the school curriculum. Physical education is typically justified as a means for students to achieve fitness and healthy lifestyles. I will argue that this instrumental justification is a weak form of argument for there are other means of becoming healthy and fit. For example, someone who walks or runs on a regular basis can achieve a reasonable fitness level and walking and running are basic motor skills which most people can achieve outside a school curriculum. Thus, a more persuasive argument for the inclusion of physical education in an educational curriculum is required. I will argue that a justification intrinsic to the notion of education which justifies physical education based on the development of practical knowledge provides a strong argument for its inclusion.

\section{Instrumental Justification}

Physical education is frequently advocated as a valuable means to helping students achieve fit and healthy lifestyles. I am not disputing this claim. The importance of fitness cannot be over-estimated. In Kretchmar's (1994) words:

\footnotetext{
Physical fitness .... affects all of us, athlete and non-athlete alike, by modifying what we can do, how long we can do it, how we feel, and how well we regard ourselves. . . . Fitness is also the closest thing we have to a necessary means value. In that fitness promotes continued life itself, it is absolutely necessary to all end values. (p. 150)
}

Although the value of fit and healthy lifestyles is not being disputed, justifying the inclusion of physical education in an educational curriculum based upon this claim is problematic because it utilizes an instrumental argument. Parry (1988) makes three objections regarding an instrumental argument. First, it is a weak form of argument because of its hypothetical and contingent nature. This is tantamount to saying, for example, that sport is of value only if it contributes to health, and it becomes a matter of contingent fact whether or not sports actually do contribute to health (Parry, 1988, p. 110). Thus, the uncertainty and temporary justification of an instrumental argument must be considered in our endeavour to justify physical education as a curriculum component. A second objection to the instrumental argument concerns the move made from a moral argument to a factual one. We begin by enquiring into the value of physical education (PE) activities, but we now find ourselves asking the quite different question of whether or not (and to what extent) a particular activity as a matter of fact serves some other value (Parry, 1988, p. 110). This move avoids the moral question by presupposing the value of health or fitness and viewing physical education as valuable only in instrumental terms. The third objection is that the instrumental argument turns the argument concerning physical education into an argument about something else-for example, health or fitness. The health-related fitness movement accepts the value of a certain definition of fitness and health, and judges all $\mathrm{PE}$ activities against this fitness/health value. No wonder such activities become marginalized (Parry, 1988, p. 110). The example 
mentioned previously of encouraging students to walk or run on a regular basis could fulfil the fitness/health value and thus obviates the need for participation in other physical education activities.

I am not denying that there are instrumental values to participation in physical education. I am only suggesting that an instrumental argument, for the reasons cited above, is not strong enough to provide a persuasive justification for the inclusion of physical education in the curriculum. To quote Parry once again, "[i]nstrumental justifications, though sometimes useful if sensibly deployed, must be seen as at best ancillary benefits to a subject which stands or falls by the strength of its primary rationale, which will be intrinsic and educational"' (1988, p. 111).

\section{A Justification Intrinsic to the Notion of Education}

In the light of much postmodern writing, the notion of a liberal education having anything to do with knowledge might seem a little passé. However, I want to revive Peters (1966) argument and then expand his conception of knowledge to include practical as well as theoretical knowledge. All of this will provide the context for revisiting Carr's (1979) intrinsic justification for the inclusion of physical education as an educational activity. 1

Peters examines processes of education and suggests that to educate someone implies not only some sort of achievement, but also one that is worthwhile. It also implies that the manner of doing this should not be morally objectionable $(1966$, p. 26). In determining what sort of achievement is worthwhile, Peters points out that the answer lies in the question-that is, to ask the question presupposes a commitment to rationality. Thus, the sort of achievement that is worthwhile is the development of rationality: "Anyone who asks seriously the question 'Why do this rather than that?' must already possess [rationality]; for it is built into this sense of 'serious.' It is impossible to give any further justification for it; for it is presupposed in all serious attempts of justification (Peters, 1966 , p. 165). The answer to the question concerning aims of education is singular-the development of rationality. Aims in education would involve tasks designed to develop rationality. Central to the development of rationality is the ability to think critically. Siegel (1988) illuminates the connection between rationality and critical thinking:

To be a critical thinker is to be appropriately moved by reasons. To be a rational person is to believe and act on the basis of reasons. There is then a deep conceptual connection, by way of the notion of reasons, between critical thinkers and rational persons. Critical thinking is best conceived, consequently, as the educational cognate of rationality. ... (p. 32)

The importance of critical thinking for the development of rationality has been recognized in current educational practice. However, what has happened to some degree is that critical thinking has been perceived as an abstract skill free from disciplinary content. Peters points out the absurdity of this situation: it is equally absurd to foster an abstract skill called critical thinking without handing on anything concrete to be critical about $(1965$, p. 104). Thus, an important task designed to develop rationality would entail the handing on of something concrete. Peters (1965) describes this as an initiation into inherited traditions: 
With the mastery of basic skills the door is opened to a vaster and more variegated inheritance. Further differentiation develops as the [student] becomes initiated more deeply into distinctive forms of knowledge such as science, history, mathematics, religious and aesthetic appreciation, and into the practical types of knowledge involved in moral, prudential, and technical forms of thought and action. ... To have a mind ... is to have an awareness differentiated in accordance with the canons implicit in all of these inherited traditions. Education marks out the processes by means of which the individual is initiated into them. (p. 103)

Thus, according to Peters, aims in education involve helping students acquire the knowledge and understanding which are part of humankind's inherited traditions. These forms of knowledge are intrinsic to the educational task of developing a rational mind. It is the intrinsic value of the knowledge and understanding developed through educational processes wherein lies a persuasive justification for physical education activities.

However, before pursuing the connection between the aim of education and aims in physical education, we must address a postmodern criticism of Peters' account of education. Hirst \& Peters (1970) suggest that the answer to the question 'What is the aim of education?' is either a conceptual truth or a persuasive definition. Following Carr (1979, I have illuminated Hirst and Peters' account which suggests that the question of the aim of education is a conceptual truth having to do with the development of rationality through knowledge and understanding. However, the criticism could be raised that this is simply a persuasive definition of education. Carr phrases the criticism as follows: [w]e have, it will be said, just preferred to define education as the development of knowledge and understanding; but people at other times and in other places have been inclined to define it differently (1979, pp. 94-5). Although there are disagreements about the nature of education, Carr points out that these disagreements are not so much about the notion that education involves the development of knowledge and understanding but rather about what sorts of knowledge and understanding are worth passing on to children or about how knowledge considered valuable should be inculcated $(1979, \mathrm{p}$. 95). It is to the question of what sorts of knowledge and understanding are worth passing on to students to which we now turn.

\section{Practical Knowledge}

In his description of education as initiation into inherited traditions, Peters alludes to the practical types of knowledge involved in moral, prudential, and technical forms of thought and action $(1965, \mathrm{p} .103)$. However, because he does not elaborate on practical types of knowledge nor refer to technical forms of thought and action, he leaves the impression that he is only concerned with theoretical forms of knowledge. Hirst, likewise, has been criticized for concentrating almost exclusively upon theoretical knowledge in the educational curriculum. In Hirst's (1974) words:

There is a central place in education for the arts and the practical, and that goes for all pupils. But the educational significance of these is limited, and any retreat from the demands of the many forms of language that are so central to human development is to set barriers to that development for many children. (Italics added; p. 28) 
In faimess to Hirst, however, it must be noted that in a more recent publication, he has retracted his overemphasis on the theoretical: "Of course, I now consider practical knowledge to be more fundamental than theoretical knowledge, the former being basic to any clear grasp of the proper significance of the latter' (Hirst, 1993, p. 197). The question which must be addressed at this point concerns the meaning and significance of practical knowledge.

Aristotle Nicomachean Ethics, VI, 5a 30) speaks of practical wisdom which he distinguished from scientific knowledge as well as art:

Therefore, since scientific knowledge involves demonstration, but there is no demonstration of things whose first principles are variable (for all such things might actually be otherwise), and since it is impossible to deliberate about things that are of necessity, practical wisdom cannot be scientific knowledge nor art; not science because that which can be done is capable of being otherwise, not art because action and making are different kinds of things. ... The remaining alternative, then, is that it is a true and reasoned state of capacity to act with regard to the things that are good or bad for man.

It is significant to note that Aristotle refers to practical wisdom as a reasoned state. From this practical reasoning, Anscombe (1957) derives the notion of practical knowledge:

A man has practical knowledge who knows how to do things; but that is an insufficient description, for he might be said to know how to do things if he could give a lecture on it, though he was helpless when confronted with the task of doing them. When we ordinarily speak of practical knowledge, we have in mind a certain sort of general capacity in a particular field; but if we hear of a capacity, it is reasonable to ask what constitutes an exercise of it. (p. 88)

Anscombe makes an important point when she states that knowing how to do things is an insufficient description for practical knowledge. Confusion has arisen over this issue and this is due, in part, to Ryle's (1949) famous distinction between "knowing that" and "knowing how":

We speak of learning how to play an instrument as well as of learning that something is the case, of finding out how to prune trees as well as of finding out that the Romans had a camp in a certain place; of forgetting how to tie a reef-knot as well as of forgetting that the German for knife is "Messer." (Italics added; p. 28)

Ryle (1949) elaborates on what it means to know how by suggesting that applying criteria in performing critically. However, he is quick to point out that when such a performance is referred to as an action exhibiting intelligence, one must be careful not to reassimilate "knowing how" to "knowing that":

"Intelligent" cannot be defined in terms of intellectual or "know how" in terms of "knowing that"; thinking what I am doing does not connote both thinking what to do and doing it. When I do something intelligently, i.e., thinking what I am doing, I am doing one thing and not two. My performance has a special procedure or manner, not special antecedents. (p. 32)

Ryle notes the infinite regress involved if one had to consider a regulative proposition before executing a performance, since one would have to consider what makes one regulative proposition more appropriate than another and this 
would involve the consideration of another regulative proposition, and so forth. Rather, Ryle proposes that it is not the parentage but the procedure which makes a performance intelligent. It is his emphasis on the overt procedure as the criterion for assessing one's ability to know how that has elicited criticism and this brings me to Carr's (1978) examination of Ryle's behaviourist approach to "knowing how."

Carr (1978) notes that we can and do meaningfully attribute "knowing how" to people who cannot themselves do the particular things in question: "It seems ... that the teaching of practical knowledge depends on this possibility", (p. 15). Carr gives the examples of a near-retirement aged physical education teacher who continues to teach his students things that he is no longer able to do or teachers who find themselves instructing students who possess far greater ability than they have in activities which they themselves are only able to perform poorly, if at all. These examples demonstrate that being able to do the activity in question is not a necessary condition for knowing how to do these activities. Being able to do the activity is also not a sufficient condition for one to be described as knowing how to do an activity. Carr gives the example of someone picking up darts for the first time and scoring a bull's eye on the first throw. This beginner's luck situation raises the question of intentionality as a critical component of practical knowledge:

In analyzing what we mean by intention, Hampshire (1959) proposes that: What I do, in the sense of try to do, I necessarily know that I do, in that use of know... in which knowing does not necessarily imply being able to state correctly. Others do not necessarily know what I am trying to do.... They have only seen or heard, or otherwise perceived or inferred, what I am trying to do. I have never perceived or inferred what I am trying to do; I have always and unavoidably known. (p. 131)

"Knowing how" differs from "knowing that" in that one cannot necessarily state correctly what one knows in the knowing how situation. There are two concepts to be examined here- the ability to state and the ability to state correctly. The knowing-how situation does not always lend itself easily to stating in verbal terms what is happening in verbal terms. However, this is not to imply that "knowing how" is devoid of conceptual content. As Hampshire points out, while we are awake and fully conscious, we are all the time acting and moving with intent, and for much of the time our thinking is practical thinking, issuing directly in intended action and not formulated in words (1959, p. 78). Ross (1988) elaborates on the employment of concepts in practical thinking:

An agent executing an intentional action is conscious of what he is doing,
and although he may not be able to express the concepts verbally, he
employs them in the judgments he renders and the decisions he makes. The
thoughts that guide and direct his actions are conceptual in nature even if
they cannot be stated propositionally; these practical concepts are manifested
in intentional actions. (p. 24)

Ross gives an illuminating example to demonstrate how judgements made during an intentional action are not always brought to consciousness. He points out that when we walk under normal circumstances, we are not consciously aware of the decisions we make regarding our action. However, if we attempt to walk on a slippery incline, all of our attention is directed to the placement of 12(2), (Spring)1999 
each step, each decision is made explicitly and we are fully conscious of thinking out each step along the way (Ross, 1988, p. 24). He suggests that a similar situation applies in the process of actions as we move in our usual manner within familiar surroundings; judging, selecting, and making decisions are inherent in action (Ross, 1988, p. 24).

Thus, although it is not always easy to verbalize what we know when we know how, the preceding examples illustrate that we can, upon reflection, state what we know how to do. The notion of state correctly raises another issue altogether-that of truth conditions. The traditional view of knowledge requires that to know $X$, one must have a justified, true belief that $X$ is so. Is there a parallel to such conditions regarding practical knowledge? Hampshire would answer in the negative: "[ $t]$ his scheme of deliberate action, and of the form of explanation appropriate to it, can scarcely be appraised as either true or false; for it is not clear what could be the basis of assessment, or what kind of evidence could be decisive" (Hampshire, 1959, p. 167).

Carr (1981) takes up the challenge of providing a basis of assessment for practical knowledge situations. For the assessment of practical knowledge, he proposes conditions parallel to those utilized for theoretical knowledge-that is, the conditions of justified, true belief. He suggests that for one to know how to do $X$, one must 1 ) entertain $X$-ing as a purpose, 2) be acquainted with a set of practical procedures for successful $X$-ing, and 3 ) exhibit recognizable success at $X$-ing. Entertaining $X$-ing as a purpose involves the notion of intentionality discussed earlier and Carr suggests that "[o]ur familiar understanding of exercises of knowing how is that they are the expressions of deliberate purposes. . just as our ordinary understanding of knowing that acknowledges that what is known is also usually believed" (1981, p. 59). The condition of being acquainted with a set of practical procedures for successful $\boldsymbol{X}$-ing is analogous to providing a justification for a propositional knowledge claim. To substantiate this claim, Carr (1981, p. 59) advocates Aristotle's notion of practical inference:

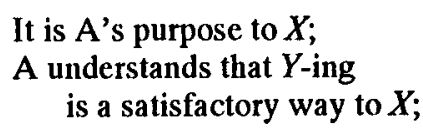

It is A's purpose to $X$;

A understands that $Y$-ing

is a satisfactory way to $X$;

Therefore, A $Y$-s.

Such a form of inference offers us a way to demonstrate just how simple or basic actions from which complicated skills are built-relate to one another as means to ends. In general, then, there is no more reason to deny that relations of a logical kind may hold between the characterizations of the individual actions that are parts of the complicated patterns of activity that are exercises of knowing how, than there is to deny that such relations also hold between the descriptions of the judgements that offer logical or evidential support for a given bit of knowing that. (Carr, 1981, p. 59)

Being acquainted with a set of practical procedures for successful $X$-ing is one condition for knowing how but the final condition involves exhibiting recognizable success at $X$-ing. This condition would be analogous to the truth condition of a propositional knowledge claim. Although Carr (1981) does admit that what one knows how to do is not a proposition but an action and, thus, can be neither true nor false, he adopts Anthony Kenny's (1966) argument that since 
practical reasoning is more closely related to imperative than to indicative reasoning, the concept of satisfactoriness rather than truth should be regarded as the validating principle.

Whereas in standard theoretical inference, the main concern is that from a set of true judgements a true conclusion should be validly inferred, what is sought through practical inferences are effective or satisfactory ways to adapt the world to often complex human purposes. . . (Carr, 1981, p. 60)

Students should bave the opportunity to acquire practical knowledge and this can only be accomplished through practical reasoning.

Learning to perform a given complex task or coming to know how to do it is essentially a matter of learning to reason practically and teaching someone how to execute a particular purpose is similarly a matter of instructing him in practical reasoning by means of practical directives; of acquainting him with rational procedures and showing him how particular ends are logically related to specific means. (Carr, 1981, p. 60)

Not to provide students an opportunity to engage in practical reasoning would leave a significant void in their education. Thus, a course such as physical education which involves a large degree of practical reasoning should be viewed as an important component of an educational curriculum.

\section{Additional Conditions for the Practical Knowledge Argument}

The justification for physical education based upon the acquisition of practical knowledge could be criticized in that utilizing Carr's conditions for assessing practical knowledge could also justify learning how to engage in the practical activities of stealing or torturing. ${ }^{2}$ To avoid this consequence, I propose that a fourth condition referring to moral acceptability be added to Carr's conditions for assessing practical knowledge. However, removing the possibility of unethical practical knowledge outcomes, we could still be left with the criticism that Carr's conditions for practical knowledge also justify the activity of belly-button scratching ${ }^{3}$ and the question can then be asked, why should physical education activities be chosen over belly-button scratching as a means to acquiring practical knowledge? I would argue that what distinguishes physical education activities from belly-button scratching, or more typical educational practical activities such as the performing of science experiments or the solving of mathematics problems, is the logical connection between moral education and physical education, as well as the possibility of the physical education class providing an arena for practising moral behaviour.

To demonstrate the logical connection between moral education and physical education, we must return to Carr's third condition for assessing practical knowledge, that of exhibiting recognizable success at $X$-ing. How could one exhibit recognizable success if he/she did not have something or someone to compare him/herself to? I have argued previously (Bergmann Drewe, 1998) that competitive situations provide this potential for comparison of one's skills. In order to demonstrate this, a revival of the root word com-petitio (to question together, to strive together) is needed. It is the notion of "together" wherein lies the opportunity provided by competitive activities for participants to grow and develop which cannot be experienced without an element of competition. It is only through comparison with others that people are able to evaluate their 
skills and abilities and it is only through continued "striving together" that people are able to realize their potential.

A key point in my argument for the necessary role of competitive activities in physical education is the notion of competition as striving together. This striving together necessitates a respect for one's opponents as well as the rules of the game. All too often, competitors lose sight of striving together to improve their skills, and the desire to win results in disrespectful actions such as trash talk, intentional injuries, and breaking the rules. Rather than avoiding competitive activities because of the potential for disrespecting rules and opponents, the necessity for moral education becomes evident. Teachers should do all that they can to instill the respect for opponents and rules which allows the competitive striving together in pursuit of excellence to flourish.

The necessity for helping students develop morally in order that they will respect their opponents as well as the rules they agreed to play by makes the physical education class an arena for the practising of moral behaviour. Some philosophers have argued that the arena provided by the physical education class can become a context for immoral rather than moral behaviour: "[W]e can readily see that sports and games can and often are taught and learned in ways that conduce to the promotion of a wide range of morally suspect beliefs, dispositions and attitudes"' (Carr, 1998, p. 129). However, the key phrase here is that sports and games can and often are taught and learned in ways that conduce to immoral behaviour. Physical education teachers have a say in how sports and games are taught. By taking the logical connection between moral education and physical education seriously, physical education teachers can create arenas for the practising of positive moral behaviour.

Although Carr (1998) argues that physical educators are in no way privileged over teachers of other subject areas regarding the opportunities for fostering positive moral behaviour, I would disagree. Regarding the importance of teaching students to respect others, physical education class would seem to provide more opportunity than a mathematics class for the degree of interaction between students. I am not suggesting that a mathematics class could not involve students working together on solving problems but mathematical problems can be solved by oneself. Games, dance, gymnastics, and outdoor pursuits, on the other hand, typically require more than one person to make the activity possible.

By engaging in games, dance, gymnastics and outdoor pursuits children could learn through the guidance of the teacher, to become tolerant of one another, to be patient and to be co-operative. (Wright, 1987, p. 101)

\section{Knowing About, In, and Through the Physical}

The preceding section involved an examination of the nature and significance of practical knowledge, as well as an explication of the logical connection between acquiring practical knowledge and the necessity of moral education. Although the teaching and learning of practical knowledge is what distinguishes physical education from more primarily theoretical knowledge components of the educational curriculum such as mathematics or history, it would be remiss of me not to examine the other areas of knowledge which constitute physical education. Peter Arnold (1991, p. 69) presents what he refers to as a 
three dimensional model of the movement curriculum which provides a suitable framework for organizing the varieties of knowledge involved in physical education. Arnold gives these dimensions catchy titles but to avoid succumbing to a mind/body dualism, we must be mindful of their metaphorical nature. Arnold (1991) refers to the three dimensions of movement as: 1) education about movement, 2) education in movement, and 3) education through movement. Education in movement refers to the practical knowledge discussed in the previous section. I will now examine the knowledge involved in education about and through movement.

Education about movement would involve the teaching and learning of theoretical and factual knowledge pertaining to the discipline of physical education. Moonier (1972) divides this knowledge into three categories: 1) knowledge and understanding directly relevant to the specific skills or activities being taught, 2) knowledge and understanding of how the body works, and 3) knowledge in related fields. Knowledge and understanding directly relevant to the specific skills or activities being taught would include not only the knowledge and understanding of skill technique but also, as Vanderzwaag (1972) points out, knowledge and understanding of the nules, etiquette, strategy, terminology and jargon, and the equipment and facilities necessary to partake in a given activity. The knowledge and understanding of how the body works would include:

knowledge of procedures in the prevention and care of injuries; knowledge of the effects of exercise on the body; knowledge of mechanical principles in the performance of skills; knowledge of relevant anatomic structure and function of body systems; knowledge about methods to develop fitness and the benefits of fitness. (Martens, 1986, p. 94)

Regarding knowledge in related fields, Zeigler \& McCristal (1967) organized the academic content of physical education into six specific areas: 1) exercise physiology, 2) biomechanics, 3) motor learning and sports psychology, 4) sociology of sport education, 5) history, philosophy, and comparative physical education and sport, and 6) administrative theory. Whether this is an appropriate organizational scheme is not the issue here-my concern is with the content of physical education's body of knowledge. What is evident is the large body of theoretical knowledge which incorporates knowledge from related fields into the discipline of physical education.

It is important to recognize that when education occurs through movement as opposed to in movement, we are speaking of movement being used in an instrumental sense. That is, participation in movement activities is being undertaken to further purposes other than the acquisition of practical knowledge. As mentioned earlier in the paper, physical education is frequently advocated as a valuable means to helping students achieve fit lifestyles. Using movement to achieve fitness is an example of education through movement. Other examples of the instrumental value of movement would include the use of movement to contribute to the development of self-knowledge, self-esteem and personhood, social education, health education, environmental education, moral education, and aesthetic education. As Meakin (1990) points out:

[c]entral to being a person is that one has a body. It seems reasonable, therefore, to claim that PE can contribute saliently to the development of personhood by assisting pupils to develop physically. (p. 115) 
Regarding moral education through physical education, Meakin emphasizes the moral values built into many competitive game rules: "[ $t]$ hat this is so can be illustrated by concrete examples of rules designed to promote fair play, consideration for others and more generally respect for persons" $(1990$, p. 118). Environmental education can be enhanced through outdoor pursuits such as hiking, canoeing, camping, skiing, and so forth. Aesthetic education can be enhanced through the appreciation of what Best (1978) refers to as aesthetic sports, such as gymnastics, diving, and figure skating. Thus, there are aspects of many physical education activities which have the potential to further other curricular purposes.

\section{The Education in Physical Education}

In the preceding section, I presented something of a misnomer when I referred to education through movement. When movement is used instrumentally to achieve purposes other than participating for the intrinsic value of the activity, it would be more appropriate to refer to such activities as meeting schooling as opposed to educational objectives. In fairness to Arnold (1991) whose three-dimensional model I have adopted, I must point out that he does make this distinction. He categorizes objectives such as those involved in moral education or aesthetic education through movement as educational objectives while objectives involving the promotion of health and fitness or social interaction as objectives of schooling (desirable but not strictly educative). To clarify this distinction, it is helpful to delve into the philosophy of education literature.

Hamm (1989, pp. 30-31) makes an important distinction between two uses of the term education: the institutional use and the general enlightenment use. The institutional use refers to formal educational institutions-that is, schools. This use of the term is the one being expressed in statements such as "I have had sixteen years of education" or "I am going to quit my job and continue my education." The general enlightenment use of the term education refers to something which may or may not go on in schools. Hamm (1989) proceeds to detail the general enlightenment use of education by examining Peters's (1966) account of education. If one reserves the term education for the general enlightenment use and schooling for the institutional use, we can make sense of the distinction made between educational objectives being met through movement and schooling objectives being met through movement. What is important to keep in mind here, however, is that both sorts of objectives are still utilizing movement in an instrumental sense.

Although I am not denying the value of using movement to promote fit and healthy lifestyles, social interaction, and so forth, or to enhance moral or aesthetic education, this attempt to justify a position for physical education in the educational curriculum neglects a much stronger justification-the justification which establishes physical education as a unique component of the educational curriculum with its primary focus on the acquisition of practical knowledge. I have proposed that such a justification is intrinsic to the notion of education and that to justify physical education based on the acquisition of practical knowledge provides a strong argument for the inclusion of physical education in the educational curriculum. 


\section{Notes}

1 In a recent issue of European Physical Education Review, 3(2), 1997, Carr expresses a lack of confidence in his earlier argument. Although he now doubts the educational (but not necessarily, schooling) value of hockey or volleyball, he has left the issue "to the future reflections of interested professionals" (p. 203). Since Carr admits that he has "not much idea what to say about hockey or volleyball" (p. 203), I would continue to advocate his earlier argument until a convincing counter-argument is put forth. tion.

2 I am grateful to Dr. Murray Elliott for bringing this point to my atten-

3 I must thank one of the anonymous reviewers of Paideusis for the belly-button scratching challenge.

\section{References}

Anscombe, G.E.M. (1957). Intention. Oxford: Basil Blackwell.

Aristotle, Nicomachean Ethics, VI, 5a 30.

Arnold, P.J. (1991). "The Pre-eminence of Skill as an Educational Value in the Movement Curriculum," Quest, 43, 66-77.

Bergmann Drewe, S. (1998). "Competing Conceptions of Competition: Implications for Physical Education," European Physical Education Review, 4, 5-20.

Best, D. (1978). Philosophy and Human Movement. London: George Allen \& Unwin.

Carr, D. (1978). "Practical Reasoning and Knowing How," Journal of Human Movement Studies, 4, 3-20.

Carr, D. (1979). "Aims of Physical Education," Physical Education Review, 2, 91-100.

Carr, D. (1981). “Knowledge in Practice," American Philosophical Quarterly, 18, 53-61.

Carr, D. (1998). "What moral educational significance has physical education? A question in need of disambiguation." In M. McNamee \& J. Parry (eds.), Ethics and Sport. London: E \& FN Spon. Pp. 35-53.

Hamm, C.M. (1989). Philosophical Issues in Education: An Introduction. New York: The Falmer Press.

Hampshire, S. (1959). Thought and Action. London: Chatto and Windus. \& Kegan Paul.

Hirst, P.H. (1974). Knowledge and the Curriculum. London: Routledge

Hirst, P.H. (1993). "Education, Knowledge and Practices." In R. Barrow and P. White (eds.), Beyond Liberal Education: Essays in Honour of Paul H. Hirsț. London: Routledge. Pp. 184-199.

Kenny, A. (1966). “Practical Inference," Analysis, 26, 65-75.

Kretchmar, R.S. (1994). Practical Philosophy of Sport. Champaign, IL: Human Kinetics.

Martens, F.L. (1986). Basic Concepts of Physical Education: The Foundations in Canada. Champaign, IL: Stipes Publishing Company. 
McFee, G. (1998). "'Spoiling: An Indirect Reflection of Sports Moral Imperative?"' Presented at the World Congress of Philosophy, Boston, MA, August 10-16, 1998.

Meakin, D.C. (1990). How Physical Education Can Contribute to Personal and Social Education. Physical Education Review, 2, 108-119.

Moonier, A.D. (1972). Physical Education: A Discussion of Principles. London: G. Bell \& Sons.

Parry, J. (1988). "'Physical Education, Justification and the National Curriculum," Physical Education Review, 11, 106-118.

Peters, R.S. (1965). "Education as Initiation." In R. Archambault (ed.) Philosophical Analysis and Education. New York: Humanities Press. Pp. 87-111. Unwin.

Peters, R.S. (1966). Ethics and Education. London: George Allen \&

Ross, S. (1988). Persons, Minds and Bodies: A Transcultural Dialogue Amongst Physical Education, Philosophy, and the Social Sciences. North York, ON: University of Toronto Press.

Ryle, G. (1949). The Concept of Mind. London: Hutchinson.

Seigel, H. (1988). Educating Reason: Rationality, Critical Thinking, and Education. New York: Routledge.

Vanderswaag, H.J. (1972). Toward a Philosophy of Sport. Reading, MA: Addison-Wesley Publishing Company.

Wright, L. (1987). "Physical Education and Moral Development," Journal of Philosophy of Education, 21, 93-102.

Zeigler, E.R., \& McCristal, K.J. (1967). "A History of the Big Ten Body-of-Knowledge Project in Physical Education," Quest, 9, 79-84. 